\title{
APPLYING CONVERSATIONAL THINKING TO THE PROBLEM OF XENOPHOBIA IN MULTICULTURAL SOCIETIES
}

DOI: https://dx.doi.org/10.4314/ajct.v1i1.5

\author{
Submission: July 2, 2021 Acceptance: October 2, 2021 \\ L. Uchenna OGBONNAYA \\ Department of Philosophy, University of Pretoria, South Africa \\ Email:1u.ogbonnaya@up.ac.za \\ ORCID: https://orcid.org/0000-0003-1322-2473
}

\begin{abstract}
Multicultural societies are faced with the problem of xenophobia - the fear, dislike, and discrimination against strangers. Xenophobia has its root in the ontology of 'the self' and 'the other', where 'the self'" is 'the indigenes' and 'the other,' 'the strangers', who must be denied the privileges and rights of the indigenes and the opportunity to contribute towards the development of their societies. In this paper, I employ conversational thinking - a method and philosophy grounded in the sub-Saharan African notion of 'relationship' as a viable theoretical option that can help us live beyond the problem of xenophobia. In conversational thinking, there are two ontological and epistemic agents, $n w a-n s a$ and $n w a-n j u$, involved in an arumaristic relationship at an ontological point, nwa-izugbe. I ground my argument in this 'arumaristic relationship' which allows for $n w a-n s a$ taken as 'the self' (indigenes) and nwa-nju, 'the other' (strangers) to come to the realm of nwa-izugbe, and exhibit nmeko (complementarity and solidarity). I contend that the notion 'nmeko', emphasized in conversational thinking, is key to putting xenophobia in the past since it stresses 'arumaristic complementary relationship' irrespective of socio-cultural and racial differences among people.
\end{abstract}

Keywords: Xenophobia, conversational thinking, multicultural societies, conversational method. 


\section{Introduction}

Two concepts stand out in my topic 1.) xenophobia and 2.) conversational thinking. Lots of articles, book chapters and monographs have been written from various perspectives. Also, lots have been written on conversational thinking as both a metaphilosophical and philopraxis (NWEKE 2015; 2016a; 2016b; CHIMAKONAM 2016; 2017; EDET 2016; CHIMAKONAM and EGBAI 2016; CHIMAKONAM and NWEKE 2018; OGBONNAYA 2018; JANZ 2018; EGBAI 2018; EGBAI and CHIMAKONAM 2019; TAVERNARO-HAIDARIAN 2018). However, there are very few that have employed conversational thinking in addressing the challenge of xenophobia. One of such work is Attoe and Azeez's "Afrophobia in Africa: A Conversational Response" (2021). Their chapter addresses a type of xenophobia known as Afrophobia using conversational thinking as its theoretical framework. While their chapter gives the impression that conversational thinking is a relevant theoretical framework for addressing xenophobia, it does so in a limited sense. For me, conversational thinking can be employed in addressing other forms of xenophobia beyond Afrophobia. Against this background, I argue that conversational thinking is existentially relevant to xenophobia. The question is, how can conversational thinking be employed to addressing xenophobia and its problems?

Philosophy is both a theoretical and practical discipline. As a discipline, philosophy seeks to understand how the society works and how society can be made better. The social dimension to philosophy is because philosophy stems from society and aims to produce ideologies that shape society. This implies that there is a correlation between philosophy and society. Society influences the philosophy it produces, and philosophy informs and shapes society. This also applies to conversational thinking.

Conversational thinking is an African culture-inspired philosophical system aimed at shaping African society and the entire human society. This philosophical system, although developed from the African philosophical place its relevance transcends the African place into the philosophical space (CHIMAKONAM 2014; 2015a; 2017a; 2017b; 2017c). Hence, it is argued to be cultural, intercultural, and transcultural. On this note, I see it as a philosophical system that could be employed to address human existential challenges across the globe. One of such human existential challenges is xenophobia.The 
concept xenophobia is deduced from two Greek words namely xenos meaning 'foreigner' or 'stranger' and phobos meaning 'fear'. Therefore, etymologically, xenophobia is the fear of foreigner or stranger. However, the meaning of xenophobia is now more complex than just this etymological meaning. It includes words such as hatred, discrimination, and even violent attack. All these words are directed at the stranger. This renders xenophobia the fear, hatred, discrimination, and violent attack against strangers. This implies that there is a bifurcating and divisive mindset wherever there is xenophobia - one that sees the other as distinct from the self, such that they are seen as contradictory opposites. Hence, the need for the self to exist without the other. A dualistic ontology and logic engineers this sort of thinking, wherein it is either the self or the other. It is the reality of this thinking pattern that makes multicultural societies xenophobic. Given that multicultural societies are culturally plural, some cultures are the self that sought to exists by negating the others' existence. This is possible when these culture groups see themselves as the indigenes and majority and others as the strangers and minority who must be excluded from their societies.

To address this existential challenge bedeviling multicultural societies, I see conversational thinking as an option to help us understand how xenophobia works and to help us live beyond it. Conversational thinking can play this role because it thrives on an ontology that makes room for two epistemic agents, nwa-nsa and nwa$n j u$ to coexist in nwa-izugbe and engage in nmeko (complementarity and solidarity). Thus, for me, this way of thinking can help us live beyond the problem of xenophobia.

In the sections that follows, I shall conceptualize xenophobia in multicultural societies. Next, I will be highlighting the salient points in conversational thinking. After that, I shall employ this philosophical system to address the problem of xenophobia in multicultural societies. And then, I shall make my conclusion.

\section{Conceptualizing Xenophobia in Multicultural Societies}

Multicultural societies consist of or relate to people of different cultural heritage and identities coexisting and intermingling. They are societies 
of diverse cultures and practices characterized with cultural diversity since they house many different cultures. There are many diverse people of different linguistic, religious, racial, ethnic, and national backgrounds in such societies. Therefore, multicultural societies are multilingual, multireligious, multiracial, multi-ethnic, and multinational. Although identified as culturally pluralistic, some cultures are kept at the peripheries while others are at center.

Therefore, such societies are divided into two groups - the majority and the minority. The majority is always the dominant cultural group, and they are usually at the center of societies and decide how they are organized and ordered economically, politically, and socially. Those termed the minority are at the margin of society. They are usually not allowed to be at the center. The point is that although these two groups of people live and work together in the same societies, they are not regarded as equals with equal privileges and rights. Hence, the discrimination that follows.

Xenophobia, which means fear, hatred, and discrimination against strangers (YAKUSHKO 2018, 11; ONI and OKUNADE 2018, $39-40$ ), poses a challenge to multicultural societies. Xenophobia is a social phenomenon that widens the existing gap in multicultural societies since it heightens the hatred and discrimination against others regarded as strangers in such societies. This phenomenon occurs along five lines in multicultural societies. These include linguistic, religious, racial, ethnic, national lines. Xenophobia can be classed as linguaphobia (linguistic xenophobia) when people are discriminated against based on linguistic differences within multicultural societies. Those of the majority language groups discriminate against those who are of the minority language groups. Members of the majority language group(s) regard those of the minority language group(s) as strangers who must not be assimilated into society. Sender Dovchin refers to this as linguistic racism (2020). I think it is appropriate to term it, linguistic xenophobia than linguistic racism.

Religiophobia (religious xenophobia) is a form of xenophobia concerned with hatred and discrimination due to religious differences. Here, people who belong to minority religion(s) are feared, hated, and discriminated against by members of the majority religion(s). One kind 
of religiophobia is islamophobia (ABDELKADER 2017; CERVI 2020) - fear, hatred, and discrimination against members of the Islamic faith. There is islamophobia in the USA and many European countries such as France, United Kingdom, Germany, Netherlands, and Sweden. In these countries, Muslims are feared and hated, and discriminated against by non-muslim (usually White) populace. This is because they (Muslims) are regarded as religious fanatics, who exhibit violent tendencies, and are intolerant towards non-Muslims, who they regard as infidels. Likewise, in the Islamic world, Christians are feared, hated, and discriminated against by most Muslims, who are the majority. Here, the minority religions are regarded as strangers while the majority religions are the indigenes. Moreover, adherents of the majority religions enjoy privileges and rights, which adherents of the minority religions are denied.

Raciophobia (racial xenophobia or racism) is another form of xenophobia that takes place along racial lines. In this form of xenophobia, people are segregated because of their race (or racial background) (TAFIRA 2018, 16). Those of the minority race is always regarded as strangers that must not be assimilated into the wider society. However, the majority race is seen as the core of society. They must be respected and given all that are due indigenes. Across the globe, Africans are considered strangers that must not be assimilated. This accounts for many scholars arguing that xenophobia in many contexts is Afrophobia (GQOLA 2008; MNGXITAMA 2008; KOENANE and MAPHUNYE 2015; DUBE 2018; ATTOE \& AZEEZ 2021)- the fear, hatred, and discriminations against Africans (people of African descent). In the words of Koenane and Maphunye, Afrophobia is "violence directed at other Africans" (2015: 83). However, some scholars seem to hold that it is not all Africans who are feared, hated, and discriminated. For them, it is a specific African group - the melanated Africans. They, therefore, describe xenophobia as Negrophobia (FANON 1967; CHINWEIZU 1994; WRIGHT 2015; KING 2021) - the fear, hatred, and discrimination against the melanated Africans and their culture. This social phenomenon is 
manifested in the USA, some parts of Europe, and even African countries.

Closely connected to raciophobia is nationophobia (national xenophobia). Nationophobia is a form of xenophobia directed against foreign nationals by the indigenes of the host nation (AKINOLA 2018: 1). For example, in the USA, Dubai, South Africa, etc., Nigerians and some other African nationals are feared, hated, and discriminated against by the indigenes of these countries. This is also found within some countries in the African countries, where the indigenes segregate against foreign African nationals, who must not be integrated into their societies. For instance, in South Africa, Nigerians and other African foreign nationals are discriminated against and not accepted as integral parts of South African society. They identify "African foreign nationals as undesirable other" (KGARI-MASONDO \& MASONDO 2019, 87), while the indigenes are the self that is an essential part of the society.

There is also ethnophobia (ethnic xenophobia). Ethnophobia is a form of xenophobia concerned with the fear, hatred, and discrimination along the ethnic line. Usually, most ethnic groups fear, hate, and discriminate against those of the minority ethnic groups. In contrast, members of the majority ethnic groups are the indigenes, while minority ethnic groups are the strangers. A manifestation of ethnophobia is the 1994 Rwandan genocide, which was aimed at exterminating a specific minority ethnic group, the Tutsi. This ethnic hatred, discrimination, and extermination, better known as ethnic cleansing, was carried out by the Hutu, the majority ethnic group (ANDRE 2018). The Hutu regard themselves as the centred and the Tutsi as the other, who are not only to be hated but must be exterminated.

From the preceding discussion, what is apparent is that multicultural societies are characterized by cultural diversity and plurality, with a near absence of cultural integration. This is because of the reality of various forms of xenophobia. While xenophobia "dehumanises the 'other' as implicitly 'different', 'alien' and 'unbelonging"' (KGARI-MASONDO \& MASONDO 2019, 87-88), the common reason for xenophobia is that strangers are believed to be the 
cause of the problems of crimes, terrorism, and economic decline in the host society.

\section{The Core Ideas in Conversational Thinking ${ }^{1}$}

Conversational thinking is a philosophical system, which has Jonathan Chimakonam as its proponent. An elite African philosophical circle known as the Conversational Society (School) of Philosophy adopted this system. This African philosophical society members are developing the system into a philosophic tradition known as Conversational tradition (conversational philosophical tradition) (OGBONNAYA 2021). The conversationalists contend that this philosophical system consists of two concepts, namely, conversation and thinking. But, what do conversationalists mean when they employ the word 'thinking' in coining the concept 'conversational thinking'?

The word 'thinking' simply means 'reflecting on something' or 'having a thought about something'. For conversationalists, thinking is conceptualized as philosophical thinking. Philosophical thinking is a 'critical and rigorous reflection' or 'having a critical or rigorous thought' on a subject matter. Chimakonam conceptualizes thinking as a philosophical questioning and answering $(2018,145)$, directed at the philosophical issues bedeviling humanity. Philosophical thinking is carried out by either an individual philosopher or a group of philosophers. If a particular philosopher carries out this reflection or thinking, it is a monologue - a selfreflection on a philosophical issue. However, where a group of philosophers carry it out, it is either a dialogue (involving two philosophers) or a polylogue (involving more than two philosophers) - a collective critical and rigorous reflection a philosophical issue of

${ }^{1}$ There are some philosophical systems such as Socrates's dialogues, Hegel's dialectics, Habermas' Discourse ethics, Oruka's dialogue with Sages, etc that seems similar to Conversational Thinking but are not. To note the distinction between conversational thinking and these other systems see Chimakonam 2015a; 2015b; 2017b; 2017c; 2018. 
concern. It is in the second sense (involving a group of philosophers) that philosophical thinking requires conversation.

Conversational is an adjectival form of the noun conversation. Conversation has both common and technical meanings and usage. The common sense and usage involve conversation being an informal exchange between and among two or more persons. This informal and ordinary exchange is translated in Igbo as mkparita-uka or nkorita$u k a^{2}$. Although, Maduka Enyimba misconceives these Igbo words for informal conversation as the conversationalists' notion of conversation, this is only a misconception (OGBONNAYA 2021; CHIMAKONAM \& OGBONNAYA 2021). While other scholars like Allan Feldman (1999), Olcay Sert \& Paul Seedhouse (2011), and even Richard Rorty (2007) have also understood conversations to be a formal exchange between two or among more than two scholars, the conversationalists, still use the term differently. Indeed, they are the first to present the idea as a system, one can say tradition, of doing (African philosophy) (CHIMAKONAM 2018, 114).

Chimakonam, the main proponent of conversationalism, derived his idea of conversation from the Igbo word arumaru-uka or iru-uka (CHIMAKONAM 2017b, 17; 2017c, 120). The word Arumaru-uka means to doubt - to doubt what is asserted by another to ascertain its veracity. Here, the essence is not just to verify the authenticity of an assertion but to unravel the inadequacies inherent in the assertion. It goes beyond this to involving reconstructing the assertion to arrive at a new assertion. This makes the conversationalists' conception of philosophical conversation a constructivist, deconstructivist and reconstructivist activity. However, an individual philosopher may not do this alone. It involves two or more philosophers. If this is the case, then conversational thinking is predicated on relationship - a rich cultural heritage in traditional Africa. This does not deny the existence of this notion in non-African societies, it only reveals the fact that relationality is a salient feature of most African societies. In traditional African societies individuals do not involve themselves in arumaru-uka unless they are in a

\footnotetext{
${ }^{2}$ These Igbo words literally mean to have an informal conversation.
} 
relationship. I am saying that it is only within the context of relationship that arumaru-uka - critical and rigorous assertion and doubting - takes place.

By merging both words, conversational and thinking, conversational thinking is coined. This can also be termed 'conversational philosophical thinking'. However, to remove ambiguity, conversational thinking is the employed coinage for this philosophical system. As stated earlier, conversational thinking is both a method and a philosophy. Conversational thinking is also known as 'conversationalism'. This method is anchored in the Igbo word, arumaru-uka. According to Chimakonam, arumaru-uka within the context of conversationalism as a method translates as "engaging in critical and creative conversation" (2017c, 120). He also contends that the notion has two meanings: "1) as a noun, 'the act' (but not the state) of engaging in critical and creative conversation; and 2) as a noun, 'the mechanism' for engaging in critical and creative conversation" (2017c, 120-121). Chimakonam without mincing words avers that these two meanings designate "a form of critical and creative relationship between or among parties" (2017c, 121). Two deductions could be made from this assertion. The first is that there are two epistemic agents involved in the relationship. These are $n w a-$ $n s a$ (i.e., defender or proponent) and nwa-nju (i.e., doubter or opponent). The second is that these two epistemic agents are involved in arumaristics (a noun deduction from arumaru-uka) - meaning "engaging in a conversational encounter" (CHIMAKONAM 2018, $145)$.

The point is that during this epistemic arumaristic relationship, nwa-nsa and nwa-nju are engaged in a ceaseless philosophical (critical and rigorous) exchange of concepts, ideas, and thoughts, which in turn leads to the generating of new ones. In this arumaristic relationship, $n w a-n s a$ asserts a position that is engaged by $n w a-n j u$. This engagement involves two phases - critical and creative. Critical engagement involves fault-finding in $n w a-n s a$ 's assertion. This is known as philosophical deconstruction. In creative engagement, the nwa-nju reconstructs the assertion into a new 
assertion. This is philosophical reconstruction. Thus, nwa-nju becomes $n w a-n s a$ and her position is also subjected to critical and creative engagement either by the former $n w a-n s a$ who takes a new position as nwa-nju or by other nwa-nju. This arumaristic relationship is not dialectics (CHIMAKONAM 2017b, 17), and therefore, there can be no creative surrender (CHIMAKONAM $2017 \mathrm{~b}, 18)$. Neither can they be epistemic conversationund (2015c: 470). If this conversational method promotes epistemic conversationund then, it will lead to a static philosophy. Conversationalism declares epistemic conversationund a philosophic anathema since reason is ever active and not passive. Hence, there is no termination of philosophical thoughts. In conversationalism, the critical and creative encounter is 'creative struggle' (CHIMAKONAM 2017b, 18; 2018, 147) involving constant reshuffling of concepts, ideas, and thoughts to form new ones. This renders conversationalism and its resultant philosophy (conversational philosophy) dynamic.

The philosophy that results from the use of conversationalism is known as 'conversational philosophy'. According to Chimakonam:

Conversational philosophy is a strictly formal intellectual engagement between or among proponents (called $n w a n s a$ ) and opponents (called nwa nju) who engage in an arumaristics1 on a specific thought in which critical and rigorous questioning and answering are employed to creatively unveil new concepts and open up new vistas for thought. (CHIMAKONAM 2017b, 116)

Although conversational philosophy involves metaphilosophy, it is aimed at addressing human existential challenges using its method (conversationalism). In this light, conversational philosophy involves the critical and creative engagement of human existential challenges or phenomenological issues by nwa-nsa and nwa-nju to propose possible solutions, which might be replaced by another solution sooner or later. 
The central thought in conversational thinking is that it is a dynamic philosophic system given that its method and philosophy are dynamic. Another idea is that it emphasizes the indispensable roles of its two epistemic agents $-n w a-n s a$ and $n w a-n j u$. These two agents are in an arumaristic relationship that is complementary. They complement themselves at a point known as nwa-izugbe (this is their meeting point). It is in nwa-izugbe that they engage their existential and phenomenological challenges and issues. This is where nmeko is activated and actualized. Nmeko (i.e., complementarity and solidarity) is possible at nwa-izugbe because neither nwa-nsa nor nwa-nju is kept at the peripheries. Both are brought into the center (nwa-izugbe) to critically and creatively engage each other on any philosophical concern. Even at this point of having functional interaction and relationship within nwa-izugbe as they engage in nmeko, these epistemic agents (nwa-nsa and nwa-nju) do not lose their identities (CHIMAKONAM \& OGBONNAYA 2021).

Conversational thinking operates with seven canons: critical conversation, theoretic interrogation, transformative indigenization, checking perverse dialogue, constructive modernization, moderate decolonization, and noetic re-Africanization. However, I will employ the first four canons to elaborate my argument in the next section. Given my objective, it is germane to state these four canons here. First, critical conversation says that an author must critically and creatively engage other authors, positions, and philosophic traditions in philosophizing. Second, theoretic interrogation opines that continuous interrogation is necessary for the progressive development of a philosophical system. In Chimakonam's words, “This interrogation involves peer-criticism, critical, but creative (re)construction of thoughts of fellow actors aimed at increasing the sophistication of the episteme" (2015a, 28). Third, transformative indigenization also known as contextual transformation. It holds that it is necessary to indigenize a philosophy, philosophic method, and non-African issues. Finally, perverse dialogue asserts that all philosophical works must be checked to preserve dialogue (2015a, 27-28). With the salient points 
in conversational thinking highlighted, it becomes necessary to apply this philosophical system to xenophobia in multicultural societies.

\section{Addressing the Problem of Xenophobia in Multicultural Societies Using Conversational Thinking}

Although multicultural societies are culturally diverse, they can hardly be said to be culturally integrated. These societies can be xenophobic, especially when some cultures are at the center while some are at the periphery. Those at the fringes or periphery of these societies are feared, hated, and discriminated by those at the center. This practice denies those at the periphery the privileges and rights that those at the centre enjoy. Hence, those at the peripheries are not given the opportunities to develop the societies they find themselves. Those at the center deny themselves the contributions of those at the margins in the development of their societies. This is like 'the self' denying itself the privilege of enjoying what 'the other' offers in developing society. 'The self' sees itself as what defines the society even without 'the other'. This can be explained and addressed using conversational thinking as a theoretical framework.

The previous section shows that conversational thinking has two epistemic agents (nwa-nsa and nwa-nju) involved in an arumaristic relationship known as nmeko (CHIMAKONAM 2018; CHIMAKONAM \& OGBONNAYA 2021). Within this context, these epistemic agents can be said to be ontological agents. And I designate them as 'the indigenes' (nwa-nsa) and 'the strangers' (nwa-nju). The indigenes are equated to 'the self', who are at the centre of their societies. And 'the strangers' are equated to 'the other' and are at the margin. This bifurcation occurs when there is a xenophobic relationship instead of an arumaristic relationship. In this ontological scenario, nmeko can hardly take place given that 'the indigenes' prevent 'the strangers' from coming to the center to complementarily contribute to their societies' development. This is like the ontological agent $n w a-n s a$ denying $n w a-n j u$ the opportunity, privilege and right to go into nwa-izugbe to engage with it in nmeko. In this scenario, we can say that $n w a-n s a$ and $n w a-n j u$ are not in complementarity and solidarity. This is the case with the practice of xenophobia of any 
form, whether linguistic, religious, racial, national, or ethnic. Xenophobia promotes strained relationship among people based on linguistic, religious, racial, national, and ethnic lines. This, in turn, prevent peaceful coexistence of people of difference and hinders the progressive development of multicultural societies, which complementarity and solidarity could have made feasible.

Nevertheless, conversational thinking abhors such strained relationships. Hence, it can function as a theoretical framework to addressing the problem of xenophobia in multicultural societies. In conversational thinking, nwa-nsa and nwa-nju are involved in nmeko in nwa-izugbe. Nmeko takes place in nwa-izugbe because both nwa$n s a$ and $n w a-n j u$ do not deny themselves the opportunity to co-exist in $n w a-i z u g b e$ (CHIMAKONAM \& OGBONNAYA 2021). However, they co-exist in nwa-izugbe; and they do so complementarily and with solidarity as they mutually engage human existential challenges within nwa-izugbe.

Given that nwa-izugbe are, in this context, multicultural societies, and nwa-nsa and nwa-nju are 'the indigenes' and 'the strangers', conversational thinking enjoins both co-exist peacefully and exhibit complementarity and solidarity. In this way, they both contribute towards the betterment of their societies. The point is that 'the indigenes' must not deny 'the strangers' the opportunities, privileges, and rights to be at the center with them and contribute towards developing their societies. Rather, both the indigenes and the strangers should in complementarity and solidarity work together to move their societies forward. The challenge is, how can this be made possible?

The four canons (critical conversation, theoretic interrogation, transformative indigenization, and checking perverse dialogue) (CHIMAKONAM 2015a) mentioned and discussed in the the previous section become relevant here. These canons can help me chart a path for the grounding of my above theoretical proposal. First, 'checking perverse dialogue'. can be construed in terms of policies that should be put in place that abhors and prevents xenophobic practices against strangers in multicultural societies. Here, policies are 
not made to favour only the indigenes, while the strangers are neglected to the detriment of society. Instead, policies should create rooms for the strangers in the fringes of the societies to be integrated into their societies regardless of their linguistic, religious, racial, ethnic, and national backgrounds. Hence, indigenes and strangers can co-exist peacefully, work in complementarity and solidarity for the common good of all and their societies.

Also, critical conversation (CHIMAKONAM 2015a) can be contextualized in terms of, multicultural societies becoming culturally integrated if and only if both the indigenes and the strangers are allowed to safely engage their collective human existential challenges and the phenomenological issues emanating from and bedeviling their immediate societies. In such societies, both indigenes and strangers engage the positions of each other critically and creatively as $n w a-n s a$ and $n w a-n j u$ do, as they seek to proffer solutions to their common existential challenges.

Closely related to critical conversation is critical interrogation (CHIMAKONAM 2015a). The critical interrogation canon can be restated as follows: multicultural societies can experience rapid development if and only if both the indigenes and the strangers continuously work together in complementarity and solidarity. In doing so, they need to engage critically and creatively, their work ethic and interrogate the institutions and policies of their societies, when it promotes xenophobia. Here, they must point out the inherent inconsistencies and therefore reconstruct them for their common good. This will help redefine their relationship with each other and place their societies on the right path to speedily progress. The point is that they will be healthy competition instead of deeply seated antagonistic rivalry that will do their societies no good.

In transformative indigenization, strangers are contextually transformed, indigenized, and integrated into their host societies. Here, they are integrated into the societies based on contextual demands and needs. I am saying that this canon makes room for strangers to have a place with the indigenes based on their contextual relevance. However, this does not transform their status from foreigner to indigenes. Just as in conversational thinking, both $n w a-$ 
$n s a$ and nwa-nju retain their status during nmeko in nwa-izugbe (CHIMAKONAM 2017b; 2017c; 2018), the indigenes and the strangers must maintain their status even though they enter a relationship of complementarity and solidarity to better their lots and their societies. Although there might be switching positions between $n w a-n s a$ and nwa-nju during nmeko conversational thinking, this does not apply to multicultural societies.

In multicultural societies, the indigenes remain indigenes and the strangers, strangers. This follows to a reasonable measure the idea of 'creative struggle' that abhors 'creative surrender' (CHIMAKONAM 2017b; 2018). Although the indigenes must allow the strangers to coexist and work with them in complementarity and solidarity, they must not surrender their place to the strangers. Not at all. The indigenes must ensure that they remain indigenes and the strangers kept as strangers. If these statuses are not maintained, then they cannot be creative struggle. In its stead will be creative surrender. If this is the case, cultural diversity would become a thing of the past. One might think that this is what I seek to establish. No! It is not what I seek to achieve. Instead, my objective is to propose multicultural societies that are culturally pluralistic by integrating other cultures. For me, in such societies, xenophobia will be absent. This is because the people will not look at their indigenes or strangers' status but engage their collective efforts in complementarity and solidarity to achieve their common good - making their societies better. This is what conversational thinking entails and projects in the face of xenophobia.

\section{Conclusion}

From my discussion so far, it is apparent that multicultural societies in being culturally diverse lack cultural integration. This is to say that xenophobia is an integral part of multicultural societies. The xenophobic tendencies and practices in multicultural societies are not primarily because strangers cause crimes, terrorism, and economic decline. Instead, it is because individuals within multicultural societies have been taught to think using the ontology of dualism. Here, the 
indigenes see themselves as the self that must exist within their societies without the strangers, the others.

Contrary to the above bifurcating and polarizing ontology that leads to xenophobia, I proposed conversational thinking as a philosophical system that helps address this problem. This philosophical system rests on a complementary ontology that sees the self and the other as integral parts of a whole (multicultural societies). Here, although they work together, their identities are retained. Hence, I argued that conversational thinking is a philosophical system that can ground the problem of xenophobia and lead us away from xenophobia. Also, I argued that the indigenes and strangers ought to involve themselves in an arumaristic relationship of complementarity and solidarity. This will help their societies develop and become better.

\section{Relevant Literature}

1. ABDELKADER, Engy. "A Comparative Analysis of European Islamophobia: France, UK, Germany, Netherlands, and Sweden," [Journal of Islamic and Near Eastern Law], pp29-63, 2015. Vol 16. No1. Paperback.

2. AKINOLA, Adeoye O. "Introduction: Understanding Xenophobia in Africa," [The Political Economy of Xenophobia in Africa, Adeoye AKINOLA Ed.], pp1-7, 2018. Springer: Cham. Paperback.

3. ANDRE, Charles. "Phrenology and the Rwandan Genocide (Frenologia e o Gencidio de Ruanda)," [Arq Neuropsiquiatr], pp277-282, 2018. Vol 76. No4. Web.

4. CERVI, Laura. "Exclusionary Populism and Islamophobia: A Comparative Analysis of Italy and Spain," Religions. pp1-21, 2020. Vol 11. No516. Web.

5. CHIMAKONAM, Jonathan O. "Conversational Philosophy as a New School of Thought in African Philosophy: A Conversation with Bruce Janz on the Concept of 'Philosophical Space'," [Confluence: Online Journal of World Philosophies], pp9-40, 2015a. Vol 18. Web. 
6.

. "Conversationalism as an Emerging Method of Thinking in and Beyond African Philosophy". [Acta Academica], pp11-33, 2017b. Vol 47. No2. Web.

7. "History of African Philosophy," [Internet Encyclopedia of Philosophy], N.P, 2014.

8.

. "The Demise of Philosophical Universalism and the

Rise of Conversational Thinking in Contemporary African Philosophy," [Method, Substance and the Future of African Philosophy, Edwin E. ETIEYIBO Ed], pp135-159, 2018. Palgrave: New York. Paperback.

9. "The End of Ubuntu or its Beginning in MatolinoKwindingwi-Metz Debate: An exercise in conversational philosophy", [South African Journal of Philosophy], pp224234, 2016. Vol 35. No2. Web.

10.

"Transforming the African Philosophical Place through Conversations: An Inquiry into the Global Expansion of Thought (GET)," [South African Journal of Philosophy]. pp462-479, 2015b. Vol 34. No4. Web.

11. _. "What is Conversational Philosophy? A Prescription of a New Doctrine and Method of Philosophy, in and Beyond African Philosophy". [Phronimon], pp115-130, 2017c. Vol 18. Web.

12. CHIMAKONAM, Jonathan O. \& L. Uchenna OGBONNAYA. [African Metaphysics, Epistemology, and New Logic: A Decolonial Approach to Philosophy], 2021. Palgrave Macmillan: Cham. Web.

13. CHIMAKONAM, Jonathan O. \& Victor NWEKE. "Why the 'Politics' against African Philosophy should be Discontinued". [Dialogue], pp277-301, 2018. Vol 57. No2.Web.

14. CHIMAKONAM, Jonathan O. \& Uti Ojah Egbai. "The Value of Conversational Thinking in Building a Decent World: The Perspective of Post-colonial Sub-saharan Africa". [Dialogue and Universalism: Journal of the International Society for Universal Dialogue], pp105-117, 2016. Vol 26, No4. Web.

15. CHINWEIZU. [On Negrophobia: Psychoneurotic Obstacles to Black Autonomy], 1994. Sundoor Publications: Lagos. Paperback. 
16. DOVCHIN, Sender. "Introduction to Special Issue: Linguistic Racism," [International Journal of Bilingual Education and Bilingualism], pp1-5, 2020. Vol 23, No 7. Web.

17. DUBE, Godwin. "Afrophobia in Mzansi? Evidence from the 2013 South African Social Attitudes Survey," [Journal of Southern African Studies], pp1005-1021, 2018. Vol 44, No 6. Web.

18. EDET, Mesembe I. "Innocent Onyewuenyi's Philosophical Re-appraisal of the African Belief in Reincarnation: A Conversational Study," [Filosofia Theoretica: Journal of African Philosophy, Culture and Religions], pp76-99, 2016. Vol 5. No1. Paperback.

19. EGBAI, Ojah Uti. "Why African Philosophers Should Build Systems: An Exercise in Conversational Thinking," [Filosofia Theoretica: Journal of African Philosophy, Culture and Religions, Workshop Special Issue]. Pp34-52, 2018. Vol. 7. No. 1. Paperback.

20. EGBAI, Uti Ojah., \& CHIMAKONAM Jonathan. "Why Conversational Thinking Could be an Alternative Method for Intercultural Philosophy," [Journal of Intercultural Studies], pp172-189, 2019. Vol 40. No2. Web.

21. FANON, Franz. [Towards the African Revolution. Trans. H. Chevalier], 1967. Grover Press: New York. Paperback.

22. FELDMAN, Allan. "The Role of Conversation in Collaborative Action Research," [Educational Action Research], pp125-147, 1999. Vol 7. No1. Web.

32. GQOLA, Pumla Dineo. "Brutal Inheritances: Echoes, Negrophobia, and Masculinist Violence," [Go Home or Die Here: Violence, Xenophobia, and Reinvention of Difference in South Africa, Shireen HASSIM, Tawana KUPE, \& Erci WORBY Eds.], pp209-221, 2008. Wits University Press: Johannesburg. Paperback.

33. JANZ, Bruce. "Conversation in Place and About Place: Response to Chimakonam, Conversational Philosophy as a New School of Thought in African Philosophy: A Conversation with Bruce Janz on the Concept of 'Philosophical Space',' [Journal of World Philosophies], pp41-50, 2016. Vol 1. Web. 
34. "The Problem of Method in African Philosophy," [Social Epistemology Review and Reply Collective], pp1-7, 2018. Vol 7. No8. Web.

35. KGARI-MASONDO, M. C., \& MASONDO, S. "“For Sake of Peace': African Language and Afrophobia," [Journal of African Foreign Affairs], pp87-102, 2019, Vol 6. No3. Paperback.

36. KING, Stephen J. "Invisibility and Negrophobia in Algeria," [Arab Reform Initiative], pp1-13, 2021. Web.

37. KOENANE, M. L. J. and K. J. MAPHUNYE. "Afrophobia, moral and political disguises: Sepa leholo ke la moeti," [The Journal for Transdisciplinary Research in Southern Africa], pp83-98, 2015. Vol 11. No4. Special edition. Paperback.

38. MNGXITAMA, Andile. "We Are Not All Like That: Race, Class and Nation After Apartheid," [Go Home or Die Here. Violence, Xenophobia and the Reinvention of Difference in South Africa, Shireen HASSIM, Tawana KUPE, \& Eric WORBY Eds.], 2008. Wits University Press Johannesburg. Paperback.

39. NWEKE, Victor C. A. "David A. Oyedola and the Imperative to Disambiguate the Term 'African Philosopher': A Conversation from the Standpoint of the Conversational School of Philosophy (CSP)," [Filosofia Theoretica: Journal of African Philosophy, Culture and Religions], pp94-99, 2015. Vol 4. No2. Paperback.

40. . "Mesembe Edet's Conversation with Innocent Onyewuenyi: An Exposition of the Significance of the Method and Canons of Conversational Philosophy." Filosofia Theoretica: Journal of African Philosophy, Culture and Religions], pp54-72, 2016a. Vol 5. No2. Paperback. . "Questioning the Validity, Veracity and Viability of the Case for 'Cogno-normative (Complementary) Epistemology': A Conversation with Chimakonam,' [Filosofia Theoretica: Journal of African Philosophy, Culture and Religions], pp109-117, 2016b. Vol 5. No1. Paperback.

42. OGBONNAYA, Lucky Uchenna. "Between the Ontology and Logic Criteria of African Philosophy," [Method, Substance, and the Future of African Philosophy, Edwin E. 
ETIEYIBO Ed.], pp113-133, 2018. Springer: Cham. Paperback.

43. ONI, Ebenezer O. and Samuel K. OKUNADE. "The Context of Xenophobia in Africa: Nigeria and South Africa in Comparison," [The Political Economy of Xenophobia in Africa, Adeoye O. AKINOLA Ed.], pp37-52, 2018. Springer: Cham. Paperback.

44. RORTY, Richard. [Philosophy as Cultural Politics], 2007. Cambridge University Press: Cambridge. Paperback.

45. SERT, Olcay., \& SEEDHOUSE Paul. "Introduction: Conversation Analysis in Applied Linguistics," [NovitasROYAL (Research on Youth and Language)], pp 1-14, 2011. Vol 5. No1. Paperback.

46. TAFIRA, Hashi Kenneth. [Xenophobia in South Africa, African Histories and Modernities], 2018. Springer: Cham. Paperback.

47. TAVERNARO-HAIDARIAN, Leyla. "Deliberative Epistemology: Towards an Ubuntu-based Epistemology that Accounts for A Priori Knowledge and Objective Truth," [South African Journal of Philosophy], pp229-242, 2018. Vol 37. No2. Paperback.

48. WRIGHT, Micah. "An Epidemic of Negrophobia," [The Black Scholar], pp21-33, 2015. Vol 45. No2. Paperback. 